\title{
Editorial: SMST 2015
}

"Has nitinol become a commodity?" This was the question I put to Dr. Tom Duerig and Dr. Keith Melton during their plenary keynote entitled "The History of our Industry" delivered to a filled lecture hall at the opening of the 2015 International Conference on Shape Memory and Superelastic Technologies. I posed the question as both Tom and Keith were instrumental in taking nitinol from the laboratories of Raychem Inc. in the 1980s to real industrial applications, particularly in the medical sector. The presentation discussed the evolution of the shape memory and superelasticity industry through the personal narratives of the speakers. The final message of the presentation was to focus on the gaps that still exist in our understanding of shape memory materials and that there is still much research to be performed.

Co-chaired by myself Dr. Neil Morgan and Dr. Keith Melton, SMST 2015 took place at Heythrop Park, in beautiful countryside on the edge of the Cotswolds region of England. Held from May 18-21, 2015, the conference was attended by 194 people and 14 industry exhibitors and was sponsored by SMST, the International Organization on Shape Memory and Superelastic Technologies. The SMST is an affiliate society of ASM International and Keith and I were very grateful for the support given by the excellent ASM staff before, during and after the conference. In addition, and on behalf of the SMST Society, Keith and I would like to thank the industrial exhibitors and sponsors listed at the end of this editorial for their financial support of the conference.

The always popular workshop on Nitinol Technology presented by Dr. Alan R. Pelton took place on the day before the main conference. The well-attended course concentrated on four key areas. How nitinol works, how to make nitinol, how to design with nitinol, and how nitinol performs. The audience included attendees from a wide range of industry sectors.

The main SMST conference focused on nitinol and other shape memory materials. I am delighted that several of the papers in this issue of Shape Memory and Superelasticity are from the 81 that were accepted for presentation at the conference.

In 2015 the International Organization on Shape Memory and Superelastic Technologies awarded the first SMST Fellowship. A Special SMST Fellowship Presentation was held during the conference. The Fellowship was awarded to Ahmadreza Jahad of the University of Toledao for his paper "Addidtive Manufacturing of Nitinol Fixation Hardware for Reconstructing Mandibular Segmental Defects". The paper was very well received and the delegates were excited at the potential of this emerging forming technique and the opportunities it opens up.

The social event at SMST 2015 was an evening to remember. Delegates were bused to the popular Turf Tavern in the nearby city of Oxford on vintage double decker buses travelling at vintage speed with vintage gear boxes! The Turf Tavern is one of the oldest pubs in Oxford with foundations dating back to 1381 and delegates spent a very sociable evening sampling fish and chips and British ale.

On the last day Dr. Keith Melton closed the conference and pondered on the excellent scientific presentations he had seen during the week, too many to mention here by name. However, during the week one thing had become obvious to Keith and I, nitinol and shape memory materials are certainly not commodities! 
Special Thanks to:

\section{SMST 2015 CONFERENCE CO-CHAIRS}

Dr. Neil Morgan, Advaniti, Ltd., United Kingdom Dr. Keith Melton, Consultant, United Kingdom

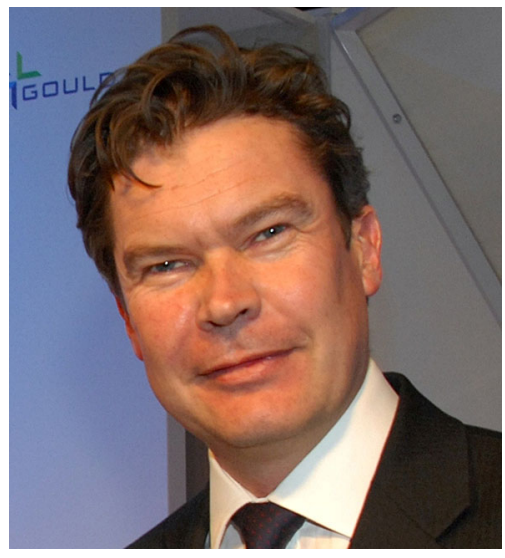

Dr. Neil Morgan, Advaniti, Ltd., United Kingdom

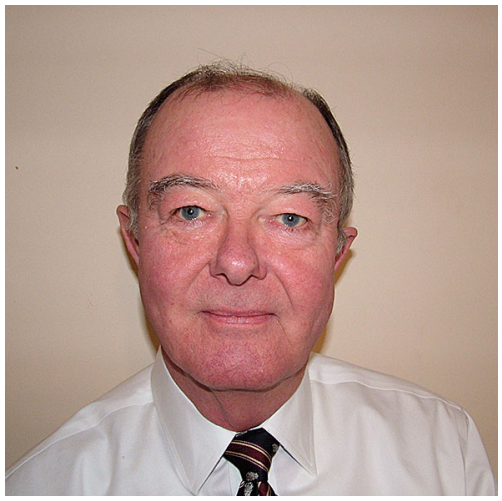

Dr. Keith Melton, Consultant, United Kingdom

\section{STEERING COMMITTEE}

Dr. Tom Duerig, Nitinol Devices and Components

Dr. Darel E. Hodgson, FASM, Nitinol Technology

Dr. Matthias Mertmann, SMST President, Memry Gmbh

Dr. Michael R. Mitchell, Mechanics \& Materials

Consulting, LLC

Dr. Alan R. Pelton, G. Rau

\section{SMST 2015 SPONSORS, SUPPORTERS AND EXHIBITORS}

Acquandas GmbH (Exhibitor)

Admedes Schuessler GmbH (Corporate Supporter, Exhibitor)

American Elements (Supporter)

ATI (Exhibitor)

Center for Advanced Non-Ferrous Structural Alloys (CANFSA) (Exhibitor)

EUROFLEX GmbH (Corporate Sponsor, Exhibitor)

Evans Analytical Group (Exhibitor)

Fort Wayne Metals (Corporate Sponsor, Exhibitor)

Furukawa Techno Material Co., Ltd. (Corporate Supporter, Exhibitor)

G.RAU GmbH \& Co. (Corporate Supporter, Exhibitor) Instron (Corporate Supporter)

Johnson Matthey (Corporate Supporter, Exhibitor)

Lumenous Device Technologies (Corporate Sponsor, Exhibitor)

MeKo Laser Material Processing (Exhibitor)

Memry Corp SAES-Smart Materials (Corporate Supporter, Exhibitor)

MTS Systems Corporation (Exhibitor)

NDC (Corporate Sponsor, Exhibitor)

Norman Noble (Corporate Sponsor, Exhibitor)

Tube Hollows International (Exhibitor)

Vascotube GmbH (Corporate Supporter, Exhibitor)

We hope to see you at SMST 2017!

Dr. Neil Morgan

Advanti Limited

Swindon, UK

Email: neil.morgan@advaniti.com 